\title{
Fin del universo y esperanza cristiana
}

\author{
MoIsÉs BRAVO GAETE* \\ Universidad Católica del Maule (Chile) \\ mbravo@ucm.cl \\ SERGIO ARMSTRONG COX** \\ Universidad Católica del Maule (Chile) \\ sarmstro@ucm.cl
}

\begin{abstract}
Resumen
El pronóstico científico de un fin del universo debido al fenómeno físico de la entropía constituye un desafío para la esperanza cristiana de una salvación del cosmos. En el presente artículo se presenta una visión general del problema planteado por la física para, a continuación, realizar un recorrido por la esperanza cristiana tal como aparece en los principales textos bíblicos y de la tradición eclesial, y culminar, finalmente, con una síntesis de la respuesta que dan dos de los autores actuales que se han ocupado del tema al problema propuesto.
\end{abstract}

Palabras clave: ciencia, fin del mundo, entropía, escatología, esperanza cristiana

\section{End of the universe and Christian hope}

\begin{abstract}
The scientific prognosis of an end of the universe due to the physical phenomenon of entropy constitutes a challenge to the Christian hope of a salvation of the cosmos. In the present article a general view of the problem posed by physics is presented, followed by a tour of Christian hope as it appears in the main biblical texts and the ecclesial tradition, and finally, a synthesis of the answer given by two of the current authors who have addressed the issue to the proposed problem.
\end{abstract} Key words: science, entropy, end of the world, eschatology, Christian hope

* Doctor en Matemáticas, Universidad de Talca y Universidad Católica del Maule, Talca, Chile. Entre sus publicaciones se encuentra "Lifshitz black holes with a time-depenent scalar field in Horndeski theory" (2014), "Planar AdS black holes in Lovelock gravity with a non minimal scalar field" (2013), "First law and generalized Cardy formula for Lifshitz black holes in new massive gravity" (2015).

** Magister en Teología, Pontificia Universidad Católica de Chile. Profesor en la Universidad Católica del Maule, Talca, Chile. Entre sus publicaciones se cuentan los libros Para leer la Historia de la Salvación (2000), Jesús de Nazaret. Sintesis de cristología bíblica (2004), Introducción a los Evangelios (2008). 
INTRODUCCIÓN ${ }^{1}$

El pronóstico científico del fin del universo constituye un desafío para la esperanza cristiana. Como se verá, las más importantes teorías existentes en la física establecen la muerte del universo en un plazo de varios billones de años debido al fenómeno de la entropía; un tema casi no abordado por la teología y al que el presente trabajo pretende ser un aporte. En un tiempo muy anterior a ese fin se habrán extinguido todas las formas de vida que puedan haber existido. $Y$ en unos 4 mil millones de años nuestro sol agotará su reserva de hidrógeno y se expandirá y acabará con los planetas más cercanos, incluyendo la tierra. En síntesis, habitamos en un mundo que no es eterno, sino finito, y formamos parte de una especie que se extinguirá más temprano o más tarde.

Ante este panorama, en los años treinta del siglo pasado, el físico británico James Jeans se preguntaba:

¿Es esto, entonces, todo lo que la vida logra, para...tropezar, casi por error, en un universo que fue claramente no diseñado para la vida y que, según todas las apariencias, es o totalmente indiferente o definitivamente hostil a ella, para quedarse aferrado a un fragmento de un grano de arena hasta que estemos congelados, para pavonearse por un breve instante en nuestro diminuto escenario con el conocimiento de que nuestras aspiraciones están condenadas a la frustración final, y que nuestros logros habrán de perecer junto con nuestra especie, dejando atrás el universo como si nunca hubiéramos estado en él? (Jeans, 1942: 15-16).

Estas previsiones de la ciencia parecen contradecir la esperanza cristiana de una salvación de la creación, presente tanto en los escritos del Nuevo Testamento como en la tradición eclesial. Baste citar como ejemplo el siguiente texto de san Pablo:

Pues la ansiosa espera de la creación desea vivamente la revelación de los hijos de Dios; porque la creación fue sometida a la vanidad, no por su propia voluntad sino por la voluntad del que la sometió, con la esperanza de que la creación misma será liberada de la esclavitud de la corrupción para participar de la gloriosa libertad de los hijos de Dios. Pues sabemos que la creación entera gime hasta el presente y sufre dolores de parto (Rm 8,19-22).

1 Este trabajo incorpora resultados del proyecto de investigación interdisciplinar Singularidad. Convergencia de filosofía, teología y ciencia de la Universidad Católica del Maule, el cual es parte del Proyecto "Science, Philosophy and Theology: Capability Building in Latin America" financiado por Templeton Fundatio, bajo una beca de investigación otorgado por la Universidad de Oxford. 
A lo largo de la historia de la Iglesia esta esperanza se fue dejando de lado y en gran medida sustituyéndose por una en la inmortalidad del alma debido a la enorme influencia del pensamiento platónico. La esperanza de un reinado de Dios como transformación de este mundo operada por el poder salvador de Dios fue cambiada por la esperanza en otro mundo: el cielo, lugar adónde van las almas. Buen ejemplo de ello es la oración medieval de la Salve:

Dios te salve, Reina y Madre de misericordia, vida, dulzura y esperanza nuestra,

Dios te salve.

A ti llamamos los desterrados hijos de Eva, a ti suspiramos, gimiendo y llorando

en este valle de lágrimas.

Ea, pues, Señora, abogada nuestra, vuelve a nosotros tus ojos misericordiosos, y después de este destierro muéstranos a Jesús, fruto bendito de tu vientre.

¡Oh, clemente, oh piadosa, oh dulce Virgen María!

La esperanza de muchos cristianos es la de salirse de este mundo, experimentado como un exilio, un valle de lágrimas y condenado a un final catastrófico según los textos del Apocalipsis (por ejemplo, en 21,1). El desentenderse del mundo ha sido la tónica dominante en la mística y reflexión eclesial y ella ha plasmado la cultura. Por eso, para muchos el problema planteado en esta introducción es inexistente: mientras el fin no sea durante esta y la próxima generación, ¿qué importancia tiene? Estaremos en el cielo o no seremos.

La inmensa lejanía del fin postulado por la ciencia puede volverlo irrelevante a los ojos de muchos: billones de años. Incluso si el fin fuera bueno, ¿que relevancia tiene si es tan lejano?

Lo que está en juego, en una mirada teológica, es el valor de este mundo nuestro a los ojos de Dios. El panorama pintado por Jeans de un universo indiferente $\mathrm{u}$ hostil a la vida pone en tela de juicio a Dios como creador y, sobre todo, como salvador. Preguntarse si este mundo tiene sentido es equivalente a preguntarse si tiene salvación. Aún un final trascendente fuera del mundo pondría en cuestión el amor de Dios por él: ¿sólo se trata de un lugar provisional, de paso?

Hace muchos años el gran biólogo y pensador religioso Pierre Teilhard de Chardin dedicaba su libro de espiritualidad, El medio divino, "a aquellos que aman el mundo" (Teilhard de Chardin, 1967: 7). Este 
modesto artículo está dedicado también a quienes quisieran un futuro de plenitud para este mundo nuestro, no sólo para sus seres humanos sino también para todas las especies que lo habitan y sus maravillas naturales.

\section{TERMODINÁMICA, ENTROPÍA Y EL DESTINO DEL UNIVERSO}

La física actual predice el fin del universo como producto de su entropía, una realidad que constituye un descubrimiento de la termodinámica, una reciente rama de esta ciencia. A continuación, se presenta en grandes líneas el surgimiento de este nuevo saber.

El descubrimiento de la máquina de vapor por parte de James Watt durante el siglo XVII dirigió la atención de la humanidad hacia el recurso natural del carbón como una riqueza fundamental para las naciones durante esa época, revelando nuevas posibilidades y etapas fundamentales dentro de la historia de la humanidad, concretándose en el proceso histórico de la denominada Revolución Industrial. Sin embargo, y en forma paralela, el estudio de la máquina de vapor y en particular del flujo del calor ${ }^{2}$ dentro de un sistema dio origen a la ciencia de la Termodinámica, convirtiéndose en una teoría que describe transformaciones de estados de la materia y la energía a nivel general, basadas en simples leyes universales, las que podemos conocer y expresar a través del lenguaje de las matemáticas y que se obtienen mediante la experimentación. Dentro de esta teoría, la descripción termodinámica de un sistema dentro de cualquier estudio conlleva a considerar barreras que separan a nuestro sistema respecto del resto del entorno. Concretamente, en la literatura es posible encontrar tres tipos de estos sistemas termodinámicos. Un sistema puede ser aislado (es decir, aquel donde no existe intercambio entre la materia y energía con el exterior), cerrado (es decir, aquel donde sólo se encuentra permitido un intercambio de energía, pero no de materia, con el exterior) y abierto (es decir, en donde se intercambia tanto la materia como la energía con el exterior), clasificándose de acuerdo a cómo interactúa con el medio exterior.

Dentro del estudio de la Termodinámica, podemos conocer el estado de un sistema en términos de variables de estado macroscópicas, clasificándolas en aquellas que son proporcionales al tamaño del sistema ${ }^{3}$, tales como el volumen, y aquellas independientes del tamaño del sistema ${ }^{4}$, como es el caso de la temperatura y la presión. En cada una de estas

2 Cuya naturaleza corresponde a una forma de energía capaz de convertirse en otras formas de energía.

3 Denominadas variables intensivas.

4 Denotadas como variables extensivas. 
variables, tanto la energía como la entropía toman un papel fundamental y matemáticamente son representadas mediante expresiones de estas variables de estado.

Resulta importante destacar que, cuando la temperatura de un sistema no es uniforme, el calor fluirá hasta alcanzar un estado de equilibrio térmico, el cual todo sistema aislado desea alcanzar, y con ello evoluciona hacia un estado donde no hay cambios dentro del sistema. Lo anterior se conoce comúnmente como equilibrio termodinámico, siendo representada mediante el Principio (o Ley) Cero, donde la evolución de un estado hacia este deseado equilibrio termodinámico se genera por medio de procesos irreversibles 5 .

Junto con el Principio Cero, existe el Primer Principio de la Termodinámica ${ }^{6}$, donde la clave fundamental es la energía y su conservación. Sin embargo, es en el Segundo Principio, conocido como uno de los más importantes de la física, donde la entropía ${ }^{7}$ que en sus inicios se definió originalmente como una función que representa la cantidad de energía no utilizable dividida por la temperatura y que actualmente corresponde a una medida de desorden de un sistema, aparece como un concepto fundamental y universal. De hecho, lo anterior obliga a considerar los procesos como irreversibles, donde la entropía siempre se incrementará, permitiendo distinguir el pasado del futuro, esto es, una flecha del tiempo (Kondepudi \& Prigogine, 1998). Un ejemplo cotidiano en donde aparece este principio es al mezclar crema con café, en donde este proceso ha cambiado de un estado de orden a uno de desorden, producto de la mezcla aleatoria entre la crema y el café. Sin embargo, revertir este proceso, resulta extremadamente engorroso. Similarmente, la frase "es más difícil construir que destruir" refleja claramente la esencia de este Segundo Principio. Finalmente, pero no menos importante, el Tercer Principio de la Termodinámica establece que no es posible, por intermedio de procedimiento alguno obtener el cero absoluto (0 grados Kelvin), cuyo valor es igual a $-273,15$ grados Celsius.

Complementando lo anterior, cabe destacar la importancia de la entropía en otras ramas de la física, no solamente en la Termodinámica. En efecto, dentro de los pilares la Física Moderna, además de la Mecánica Cuántica, se encuentra la Relatividad General, teoría elaborada por Albert

\footnotetext{
5 Es decir, en aquellos procesos que no son reversibles en el tiempo. Desde este enfoque, tenemos que todos los procesos de la naturaleza los podemos clasificar como irreversibles.

6 Cuya base se encuentra gracias a los trabajos experimentales del científico James Prescott Joule (1818-1889).

7 Definida por Rudolf Clausius (1822-1888), cuyo nombre proviene del griego entropía, que significa transformación o cambio.
} 
Einstein (1916). Su belleza y simplicidad se encuentra en que sus ecuaciones permiten en primer lugar fusionar el espacio y el tiempo en una nueva unidad denominada espacio-tiempo, además de estudiar la interacción entre la materia y la gravedad, asociando esta última a una noción puramente geométrica. Al resolver estas ecuaciones, aparece uno de los resultados más atrayentes presentes en el universo, los agujeros negros. Éstos se pueden definir de manera intuitiva como una región finita del espacio-tiempo capaz de generar un campo gravitatorio tal que ninguna partícula (ni siquiera la luz) puede escapar, envuelta por una región denominada horizonte de eventos. Junto con lo anterior, gracias a los trabajos elaborados por Bardeen, Carter y Hawking (1973) en la década de los setenta, nos permiten dilucidar que estas configuraciones se comportan como un sistema termodinámico y que existen cuatro leyes que gobiernan su comportamiento, que poseen una notoria similitud con las leyes termodinámicas básicas presentes en la literatura, permitiendo encontrar una estrecha relación entre la Gravedad, la Termodinámica y la Teoría Cuántica. Más todavía, dentro del marco de la Teoría Cuántica, Stephen Hawking mostró que los agujeros negros son capaces de emitir radiación, con una temperatura característica (Hawking, 1975), que depende explícitamente de una expresión conocida como gravedad de superficie; y Jacob Bekenstein se percató que poseen una entropía, que es proporcional al área del horizonte de eventos (Bekenstein, 1973), utilizando como argumento la teoría de la información ${ }^{8}$, en donde el Segundo Principio se traduce en que la entropía del sistema aumenta, debido a la pérdida de la información de la configuración interna del sistema producto de su evolución.

De las ecuaciones de Albert Einstein podemos obtener teóricamente la cantidad de materia-energía presente en nuestro universo y, de hecho, estimar una densidad promedio crítica de éste. Si esta densidad se calcula y resulta menor a este valor crítico, obtendremos una expansión eterna, hasta obtener una temperatura cercana al cero absoluto. En caso contrario, la expansión se invertirá hasta alcanzar temperaturas extremadamente altas dentro del denominado "Big Crunch" (Kaku, 1995: 300).

Si suponemos por unos momentos un universo en expansión y como un sistema aislado, donde no existe nada fuera de éste, tenemos que la entropía global crece con el tiempo, lo que coincide plenamente con el Segundo Principio de la Termodinámica, llegando a un estado de entropía máxima, junto con un estado de equilibrio termodinámico. Lo anterior permite predecir, considerando una escala de cientos de billones de años,

8 En donde la entropía es una medida de la falta de información acerca de la configuración interna de un cierto sistema. 
que puede haber un final para el universo, denominado como muerte térmica, en donde no es posible establecer condiciones para la vida. Este aumento de la entropía también se encuentra asociado a sistemas más pequeños, tales como planetas y estrellas. En particular, el Sol, considerado como una estrella de mediana edad, tendrá el mismo fin de nuestro universo. En efecto, cuando este gigante consuma completamente su combustible de Hidrógeno, pasará a quemar el elemento Helio, aumentando sustancialmente su tamaño, convirtiéndose en un gigante rojo y abarcando regiones más allá de la órbita de la Tierra, acabando con la vida y la Tierra misma. En general, para una estrella, el agotamiento de su combustible debido a energías nucleares internas, produce que éstas se conviertan en estrellas enanas frías, de neutrones o en agujeros negros, dependiendo de su masa inicial, hasta que estas fuerzas nucleares cesen y conduzcan a una muerte segura. Esta muerte encadena de las estrellas producirá un universo oscuro, lo que en billones de años más, de acuerdo a la Teoría de la Gran Unificación, producirá una desintegración de los protones y neutrones, debido a sus inestabilidades sobre esta vasta escala de tiempo, y toda la materia conocida se desintegrará en partículas más pequeñas, tales como electrones y neutrinos. Luego de un periodo extremadamente extenso, la temperatura del universo se acercará al cero absoluto, pero a pesar de ello, aún perdurarán los agujeros negros pues, tal como se explicó anteriormente, liberan una pequeña cantidad de energía hasta el exterior (Kaku, 1995).

De acuerdo a algunos astrónomos, queda la pregunta abierta de qué ocurrirá en el universo luego de la inimaginable cantidad de $10^{100}$ años, cuando los últimos vestigios de agujeros negros en evaporación hayan consumido completamente su energía. Sin embargo, existen especulaciones alternativas, asociadas a la Teoría Cuántica que abre las posibilidades de otros universos y, por ejemplo, luego de este transcurso de tiempo, nuestro universo pueda pasar por medio de una especie de "efecto túnel" a otro universo (Kaku, 1995: 306).

Como conclusión final de esta sección, sea cual sea la teoría considerada (en expansión en baja temperatura o contracción a alta temperatura), pareciera ser que la muerte del universo resulta inevitable y podemos colegir irrefutablemente que cualquier vida inteligente, además de la nuestra, sin importar lo avanzada que sea, perecerá cuando el universo muera.

2. EL FIN DEL MUNDO EN LA REVELACIÓN BÍBLICA Y MAGISTERIO ECLESIAL

Corresponde ahora abordar el problema planteado por la física con el 
método propiamente teológico que recurre a la autoridad de Dios mismo expresada en la doble vertiente de las Sagradas Escritura y de la Tradición.

Un recorrido completo por ambas sería demasiado extenso. Por tanto, haremos una selección de lo que nos parece más relevante.

Aunque nos remitiremos sólo al Nuevo Testamento, es conveniente traer a colación la noción del tiempo propia de la mirada bíblica. Este consiste en una recta ascendente en que el futuro es diferente del presente y del pasado. La esperanza siempre mira al porvenir debido a las promesas de plenitud dadas a Abraham y en la revelación neotestamentaria a las promesas de Jesús. Ambas integran siempre la dimensión cósmica. En efecto, es impensable una salvación que lleve a plenitud al ser humano sin que ella implique también al entorno en que él se mueve y con el que se relaciona tan hondamente.

Es posible distinguir, siguiendo a Bollini (2007), dos vertientes en la tradición neotestamentaria: una que propugna un reemplazo de este mundo (dado su caducidad) por una realidad nueva y mejor y, otra, que concibe el fin como una transformación plenificadora de este universo por una acción divina especial.

Ambas corrientes parecen estar presente ya en Jesús mismo. En efecto, él anuncia un Reinado de Dios que se está desplegando ya en la historia presente en sus milagros, en las buenas nuevas a los pobres, en la comunidad de los discípulos (Mt 11,2-6; Lc 10,17-24). Y, por otra parte, un gobierno de Dios que está por venir, tal como aparece en el padrenuestro ("Venga tu reinado": Mt 6,10). Ambos anuncios no son contradictorios, sino que obedecen a dos etapas en el gobierno divino: una modesta, germinal, en medio de las vicisitudes de la historia y otra plena, sin ambigüedades y definitiva. Ambas están presentes en las llamadas "parábolas de crecimiento": la semilla de mostaza (Mc 4,30-32); de la levadura (Mt 13,33); del agricultor paciente (Mc 4,26-29); del trigo y la cizaña (Mt 13,24-30). En estas parábolas se compara un estado inicial, muy modesto, con uno final, esplendoroso; sin embargo, entre ambos hay un punto de unión, un proceso que va de principio a fin. Proponen una transformación gradual de nuestro mundo (no necesariamente lineal) que lo lleva a un estado de plenitud.

Sin embargo, también está presente en el mensaje de Jesús un aspecto de discontinuidad, de ruptura, como puede verse en su descripción de la venida del Hijo del hombre:

Pasado el sufrimiento de aquellos días, el sol se oscurecerá y la luna no dará resplandor; las estrellas irán cayendo del cielo y las fuerzas celestes se tambalearán.

Entonces, verán venir al Hijo del hombre entre nubes con gran poder y 
gloria. Él enviará entonces a los ángeles y reunirá de los cuatro vientos a sus elegidos, desde el extremo de la tierra al extremo del cielo (Mc 13,24-27).

Presentamos dos textos neotestamentarios de una línea "rupturista": 2 P 3,3-13 y Ap 21.

La segunda carta de Pedro está escrita por un miembro desconocido del círculo petrino a fines del siglo I o principios del siglo II (Cervantes, 1995). El pasaje que nos ocupa es una reacción ante "falsos profetas" y "falsos maestros" que están introduciendo herejías y prácticas libertinas en la comunidad. Ellos preguntan sarcásticamente "¿dónde está la promesa de su Venida? Pues desde que murieron los Padres, todo sigue como al principio de la creación" (2 P 3,4).

El autor de la carta recuerda que antes existió un mundo (cielos y tierra) distinto que pereció por las aguas del diluvio y que otro tanto ocurrirá con el mundo actual que será consumido por el fuego $(3,5-7)$. Con la llegada del Señor el firmamento y la tierra se derrumbarán y disolverán ardiendo $(3,12)$. Para concluir finalmente que "esperamos, según nos lo tiene prometido, nuevos cielos y nueva tierra, en los que habite la justicia" $(3,13)$.

En Ap 21,1 se nos dice con mucha claridad: "Vi un cielo nuevo y una tierra nueva porque el primer cielo y la primera tierra desaparecieron, y el mar no existe ya". No se trata de una novedad absoluta ya que la nueva Jerusalén nos recuerda a la anterior y el nuevo mundo tiene mucho de los rasgos del antiguo. Sin embargo, se acentúan más los rasgos de discontinuidad entre ambas creaciones que los de la continuidad.

En la posición opuesta, que privilegia la continuidad por sobre la discontinuidad, presentamos dos textos: Col 1,18-20 y Rm 8,18-22.

El primero nos dice sobre Jesucristo:

Él es también la Cabeza del Cuerpo, de la Iglesia,

Primogénito de entre los muertos, para que sea Él el primero en todas las cosas, pues Dios tuvo a bien hacer residir en Él (en) toda la plenitud (pléroma), y reconciliar todas las cosas por Él (diâ) y para Él (éis)

pacificando por la sangre de su cruz

lo que hay en la tierra y en los cielos.

Pablo o un discípulo suyo (se discute si Colosenses es carta paulina) nos presenta la supremacía de Cristo en el orden de la salvación afirmando que Cristo es la cabeza del cuerpo que es la Iglesia; lo que significa que es la fuente que comunica la vida a los miembros del cuerpo y los une en un conjunto vital y armónico. A la afirmación de que Cristo es principio de 
todo, por su condición divina, se añade que Cristo se nos ha manifestado en la Pascua como "el primogénito (protótokos) de entre los muertos". Lo es no sólo en cuanto que fue el primero que resucitó, sino en cuanto que en la resurrección de Cristo ya está incluida la de todo ser humano (1 Co 15,20), que tendrá lugar al final de los tiempos (2 Co 4,14).

La "plenitud" (pléroma), que habita en Cristo significa que en Cristo, y sólo en él habita efectiva y esencialmente la divinidad. Y no la comparte con las potencias cósmicas ni con los ángeles. Estos son, como todos los demás seres de la creación, creaturas suyas (Pérez, 1995; Mora, 2007).

¿Qué significa “...reconciliar todo”? Según Bollini:

diferentes textos del NT afirman que toda la creación ha de ser devuelta a Dios (Romanos 8,19-23; Marcos 16,15). La creación está alienada y su armonía perdida a causa del pecado del hombre. Existía una creencia judía de que el mundo había caído en cautividad bajo los poderes rectores que residen en él, a causa del pecado del hombre. Cristo los derrotó, y les arrebató el dominio sobre los creyentes (Bollini, 2007: 133).

Como puede verse, es este mundo, el que Cristo reconcilia y lleva a su plenitud. Un suceso que se realizará en plenitud sólo al final de los tiempos. No se trata de una nueva creación, sino de una transformación de la antigua.

Otro texto clave en esta misma línea es Rm 8,18-22 (Barbaglio, 1990; Wilkens, 1992):

Porque estimo que los sufrimientos del tiempo presente no son comparables con la gloria que se ha de manifestar en nosotros. Pues la ansiosa espera de la creación desea vivamente la revelación de los hijos de Dios. La creación, en efecto, fue sometida a la vanidad, no espontáneamente, sino por aquel que la sometió, en la esperanza de ser liberada de la servidumbre de la corrupción para participar en la gloriosa libertad de los hijos de Dios. Pues sabemos que la creación entera gime hasta el presente y sufre dolores de parto.

Pablo comienza hablando a los cristianos de Roma y contrapone su presente lleno de dificultades a un futuro de plenitud junto a Dios. Afirma que el mundo creado ha sido puesto bajo el dominio de la nulidad o vanidad. Esta palabra mataiótes, propia de la propaganda misionera del cristianismo que la ha heredado del Antiguo Testamento y del Judaísmo, indica el vacío espiritual y la insignificancia en que la adoración de los ídolos ha hecho hundirse a los negadores del único Dios verdadero. El apóstol la atribuye al cosmos, pero no sin precisar que la causa de tal proceso de degradación no ha sido el mundo, sino "aquel que la sometió 
(a la creación)". La expresión no precisa el sujeto de la frase. Con probabilidad se refiere a Dios que así reacciona a la rebelión de Adán, prototipo de la humanidad pecadora $(5,12)$.

"En la esperanza de ser liberada de la servidumbre de la corrupción". Dios, al someter la creación a la vanidad, dispuso conjuntamente también la futura eliminación de ésta. "Servidumbre de la corrupción”es sinónimo de "vanidad".

"Para participar en la gloriosa libertad de los hijos de Dios". Al introducir a los cristianos en su "gloria", Dios libera a toda la creación, por eso ella espera ansiosamente ese momento. Se piensa, pues, no en una gloria propia de los cristianos sino en la gloria de Dios, en la que ha recibido a Cristo Resucitado como a su Hijo y de la que hará partícipes a los cristianos como coherederos de Cristo. Vale la pena reparar en que al compartir su gloria Dios crea libertad. Dios es Dios como el que libera de la esclavitud.

Los dolores que atribulan a la humanidad no son estertores de la muerte, sino dolores de un nuevo nacimiento. El verbo sunodino aquí es usado para aludir a los sufrimientos del parto, imagen clásica en la literatura apocalíptica para indicar la tribulación de la historia como síntoma de la próxima venida del nuevo mundo. Sin embargo, a diferencia de la apocalíptica, aquí en ningún momento se habla de un cielo nuevo y una nueva tierra. Es este mundo quien será liberado mediante una transformación radical.

Junto con las Escrituras, la tradición eclesial constituye una de las fuentes de la revelación de Dios. Hacer un recorrido mínimamente completo de la tradición es aquí imposible. Sin embargo, me parece acertado el sucinto resumen de los principales momentos de estas ideas, que hace Bollini (2007), basándose en el recorrido realizado por Papanicolau (2005) a partir de la obra de Galloway (1952).

Según esta síntesis, los Padres alejandrinos intentaron sostener la redención cósmica, pero bajo la influencia de la filosofía griega con su menosprecio de la materia, carecieron del énfasis necesario acerca de la bondad de ésta, mientras que en Occidente (especialmente con San Ireneo) repitieron con escasa creatividad la doctrina del judaísmo de la redención física del cosmos. En la Edad Media la doctrina de la resurrección impulsó a los teólogos a incluir al cuerpo humano en el alcance de la redención, pero manteniendo una dicotomía entre naturaleza y gracia que les impidió extender tal rescate al universo físico. En la época de la Reforma, no hubo espacio para la reflexión sobre la redención cósmica, pues se puso énfasis en la experiencia interior. Posteriormente, la revolución científica moderna tomó al mundo físico como un sistema autónomo sin significado trascendente, relegando una vez más lo religioso 
a lo personal.

El Magisterio Eclesiástico se pronunció en escasas oportunidades sobre el futuro del cosmos (Ruiz de la Peña, 1996). Se dirigió a evitar posiciones extremas que postulaban la ausencia de un futuro escatológico para el cosmos no espiritual, en el Sínodo de Constantinopla de 543 (c.11) y el Concilio de Constantinopla II (553). Hay que esperar al Concilio Vaticano II para tener declaraciones de tipo propositivo.

El Concilio Vaticano II (2000a), en la Constitución Dogmática Lumen Gentium (n.48) considera el aspecto escatológico como fundamental para la Iglesia como Pueblo de Dios, incluyendo la dimensión cósmica, mientras que en la Constitución Pastoral Gaudium et Spes, la doctrina escatológica se presenta desde el dinamismo del trabajo humano como preparación del Reino de Dios. A continuación, citamos una parte de este texto:

Ignoramos el tiempo en que se hará la consumación de la tierra y de la humanidad. Tampoco conocemos de qué manera se transformará el universo. La figura de este mundo, afeada por el pecado, pasa, pero Dios nos enseña que nos prepara una nueva morada y una nueva tierra donde habita la justicia, y cuya bienaventuranza es capaz de saciar y rebasar todos los anhelos de paz que surgen en el corazón humano (...) (Concilio Vaticano II, 2000b, n. 39).

¿Se trata de una nueva tierra o de una trasformación de este mundo? El Concilio no quiso zanjar la cuestión y el texto mantiene la ambigüedad entre estas posibilidades. Debe destacarse que el Concilio constituyó un impulso para el estudio de la escatología cristiana.

\section{REFLEXIÓN ACTUAL}

Son muchos los autores que en el siglo XX y XXI se han ocupado del tema de la escatología en general y del fin del cosmos en particular. Sin embargo, muchos menos son los que han integrado los descubrimientos de la física en dicha reflexión?. En cuanto al desafío de la entropía, este grupo se reduce a tres: John Polkinghorne, Robert Russell (según Bollini 2007) y Claudio Bollini. Nos inclinamos en esta parte por realizar una comparación entre los pensamientos de Polkinghorne y Bollini por su

\footnotetext{
9 Se trata de los llamados científicos-teólogos. Los más importantes son Ian Barbour, Arthur Peacocke, Robert Russell, John Polkinghorne, Frank Tipler, Freeman Dyson y Paul Davies.
} 
profundidad, novedad y diversidad ${ }^{10}$.

John Polkinghorne es presidente del Queens' College de Cambridge y miembro de la Royal Society. Es un antiguo profesor de física matemática, que posteriormente comenzó a desempeñarse como pastor en la Iglesia Anglicana y a reflexionar desde su doble condición de teólogo y físico.

Claudio Bollini es doctor en teología y programador científico. Es hijo de un connotado físico argentino. Realizó su tesis doctoral precisamente en el tema del desafío que planteaba la entropía a la esperanza cristiana en un fin plenificante del universo. Tiene numerosas publicaciones sobre el tema y trabajos interdisciplinares sobre ciencia y fe cristiana.

La escatología de Polkinghorne (2002; 2007) se enraíza en la cuestión del hombre y su relación con Dios: si los seres humanos son amados por el Creador, entonces deben tener un destino más allá de sus muertes. Nuestro autor, sin embargo, tacha de dualista la concepción de un alma encarnada, y puntualiza que la esperanza no se funda en la supervivencia de la muerte de un alma intrínsecamente inmortal, sino en la resurrección del hombre íntegro. Ésta es posible gracias al incondicional amor del Creador, que no permitirá que las creaturas que ama caigan en la nada, pues es Dios de los vivientes. Este compromiso divino está fundamentado y testimoniado en la misma resurrección de Jesucristo.

En última instancia, la esperanza escatológica nos dice que ningún bien se perderá definitivamente en el Señor. En el Nuevo Testamento existen pistas respecto de cómo la acción divina se extiende a toda su creación: la teología paulina habla con claridad de la redención cósmica. En Col 1,15s, Pablo habla de modo sorprendente del significado de Cristo en términos cósmicos, como Aquel que reconcilia y pacifica, mediante su cruz, todo lo creado. Asimismo, es fundamental el texto de Rm 8,19-23, al que Polkinghorne califica de uno de los más notables pasajes de todo el Nuevo Testamento.

Polkinghorne, distingue entre una antigua creación y una nueva. A su juicio, la primera creación fue ex nibilo (de la nada), mientras que la creación nueva será ex vetere (a partir de la vieja). En sus palabras:

la creación vieja es la acción de Dios que lleva al ser a constituirse en un universo que es libre de existir 'por sí mismo', en el espacio ontológico que le ha sido dado por el acto kenótico divino de permitir la existencia de algo completamente distinto (Polkinghorne, 2007: 242).

Esta compleja frase requiere de una explicación. Polkinghorne toma

10 Utilizaremos para ello dos obras de Polkinghorne (2002 y 2007) y dos de Bollini (2007 y 2010). 
de Moltmann (1987) la idea de que Dios antes de crear genera un espacio libre de su presencia y su poder, esencial para la autonomía que su obra va a necesitar. Su creación será después gradual, lenta y laboriosa, no exenta de sufrimiento. El "abajamiento" (kénosis) del Hijo de Dios del que habla el himno de Filipenses (Flp 2) refiriéndose a la encarnación, comienza ya en la creación, con esta retirada de su poder y con su paciencia casi infinita.

Polkinghorne (2007) explica que esta creación vieja tiene la habilidad de hacerse a sí misma a través de una mezcla de exploraciones surgidas al azar, aludiendo al proceso de selección natural. Es un universo que no está fuera del cuidado sustentador y providente de Dios, pero al que se le otorga la debida independencia para seguir su propia historia. Este proceso histórico no puede evitar el costo del sufrimiento, que es el precio de la independencia. Tiene un gran potencial para generar vida, pero no de mantenerla; en ella la muerte es el costo de una nueva vida.

Es una creación sostenida por su Creador, y que ha sido dotada de una fecundidad divinamente intencionada, pero que también está a cierta distancia de la presencia velada de Aquel que la sostiene en el ser e interactúa de maneras ocultas con su historia. Sus procesos desplegados se desarrollan dentro del 'espacio' que Dios les ha dado, dentro del cual se le permite ser él mismo.

El mundo futuro tendrá que tener un carácter diferente. Tal como Jesús fue exaltado a la diestra del Padre después de su resurrección, así el mundo venidero será integrado de una manera nueva e íntima con la vida divina. Como Pablo escribió a los corintios, Dios será entonces "todo en todos" (1 Co 15,28). Los ortodoxos orientales hablan del cumplimiento escatológico como el logro de la "divinización" (teosis), no entendiendo por ello que las criaturas se convertirían en dioses, sino que compartirán plenamente la vida y energías divinas. La nueva creación será completamente sacramental, impregnada con la presencia de la vida de Dios. El Apocalipsis, en su gran visión del fin, ve la ciudad santa como una en la que no hay más templo cultual "porque su templo es el Señor Dios El Todopoderoso y el Cordero" (Ap 21,22). La presencia de Dios, velada para nosotros hoy, será abierta y manifiesta en el mundo por venir.

Parece una esperanza coherente creer que las leyes de su naturaleza estarán perfectamente adaptadas para la vida eterna en aquel mundo donde "La muerte no será más; el luto y el llanto y el dolor no serán más, porque las primeras cosas han quedado atrás" (Ap 21,4), así como las leyes de la naturaleza de este mundo actual perfectamente están adaptadas al carácter de su libre proceso evolutivo, a través del cual la vieja creación se ha hecho a sí misma. En este universo, el espacio, el tiempo y la materia están mutuamente interconectados en el paquete único de la relatividad general. Parece razonable suponer que este vínculo es una característica 
general de la voluntad del Creador. Si es así, la nueva creación también tendrá su espacio y tiempo y materia. La más significativa consecuencia teológica de esta creencia es la expectativa de que habrá "tiempo" en el mundo porvenir.

La continuidad igualmente necesaria entre la vieja y nueva creación reside en el hecho de que esta última es la transformación redimida de la primera. El modelo para esto es la resurrección de Cristo donde, como ya hemos enfatizado, el cuerpo resucitado del Señor es la transformación escatológica de su cuerpo muerto. Esto implica que la nueva creación no surge de un acto creativo radicalmente nuevo ex nibilo, sino como un acto redentor ex vetere, a partir de lo viejo.

La pregunta apremiante de por qué el Creador ha traído a la existencia este valle de lágrimas si pudo eventualmente crear un mundo libre de sufrimiento, aquí encuentra su respuesta. La intención creativa total de Dios se ve intrínsecamente como un proceso de dos etapas: primero la creación antigua, permitida para explorar y realizar su potencialidad en cierta distancia metafísica de su Creador; luego la nueva creación redimida que, a través del Cristo Cósmico, es llevada a una libremente estrecha e íntima relación con la vida de Dios.

Una consecuencia adicional de esta comprensión es que establece claramente el valor de la vieja creación, ya que ella proporciona la "materia prima" para la transformación escatológica en la nueva creación. El deber de cuidar de este mundo actual sigue en pie.

Polkinghorne (2002) se opone a una intervención extraordinaria de Dios (un tour de force) en la vieja creación que arregle simplemente, mediante el ejercicio de su poder, lo que quedaría, si no, fuera de control. La larga historia de la evolución cósmica nos pone ante un Dios de proceso y no de magia, un Dios que es paciente y sutil a la hora de alcanzar sus intenciones.

Es importante notar que Polkinghorne (2002) está afirmando, de forma indirecta pero inequívoca, que la creación actual va a perecer y que la nueva creación sustituirá a la antigua. Es cierto que la nueva creación conservará y llevará a plenitud lo mejor de la antigua, pero se trata de un nuevo mundo, de un nuevo universo.

Bollini tiene una visión diferente y en gran medida opuesta a la de Polkinghorne. Afirma una redención escatológica de este universo:

En definitiva, sea que se anuncie la caducidad y conclusión de la presente historia o se observen los gemidos de la entera creación suspirando por el final alumbramiento; sea que se proclame el advenimiento de los cielos y la tierra nueva o se advierta que es esta misma creación el sujeto de la renovación futura; en cada uno de estos casos los Autores Sagrados y los 
Padres de la Iglesia han comprendido inspiradamente que, así como el ser humano no fue abandonado a su propia suerte, cercado por los callejones sin salida de sus límites y miserias, tampoco Dios habrá de relegar al total olvido esa realidad que le es co-extensiva: su hogar, su infraestructura, su ámbito de desarrollo y humanización. De una u otra forma, póngase el énfasis en la identidad o en la novedad, permanece una generalizada intuición: también esta dimensión habrá de ser, de algún modo, conjuntamente librada en la Parusía (Bollini, 2010: 88-89).

Asimismo, postular una resurrección de todo lo creado es altamente problemático, pues plantea ciertas dificultades serias basadas en la especificidad espiritual del hombre y los límites de su analogabilidad: la resurrección del hombre no acontecerá de la nada, sino a partir un principio vital que habrá de subsistir, a saber, el alma, realidad espiritual sólo donada al hombre y de la cual el universo carece.

Pero si, aun así, quisiéramos aplicar este concepto al cosmos, afirma Bollini (2010), deberíamos primero considerar que éste debe desembocar en un estado de muerte a partir del cual sea posible una resurrección; en el caso del universo tomado como un todo, esto significa la total y completa esterilidad, puesto que no cabe ya esperar ningún proceso físico ulterior. Esto presentaría la dificultad de la derogación de todo sustrato mínimamente estructurado que Dios pudiera asumir para que no fuese, desde un punto de vista físico, una creación ex nibilo. Cabría preguntarse conjuntamente cómo podría anunciarse la esperanza de la Venida de Cristo a una humanidad aún peregrina ante semejante panorama, invalidante de cualquier forma de vida, sea racional o no. En suma, Bollini no considera que la resurrección universal del hombre sea directamente analogable con el resto del cosmos, y que tampoco en el mero nivel simbólico constituya la más logradas de las metáforas. En lugar de pensar en el cosmos en términos de muerte-resurrección, le parece más adecuada la dualidad redención-transformación. En efecto, la redención no puede sino concebirse a partir de un ser vivo.

Así pues, concluye Bollini (2010), podemos esperar que, de forma consonante a la redención del hombre, y con similar acto de absoluta gratuidad, Dios rescatará al cosmos antes de su muerte final, destino inevitable en caso de no haber Él intervenido.

Pero la recreación divina no acontecerá de la nada, sino a partir de la misma materia y estructura del cosmos, es decir, asumiendo su capacidad natural de generar novedad con la que Él mismo dotó a su creación. Santo Tomás (citado por Bollini, 2007) expone dos agudos conceptos que deben leerse complementariamente: Por un lado, desde su mismo génesis, Dios ha infundido una potencia en toda creatura para que fuera capaz de recibir 
la innovación escatológica. A continuación, precisa que tal innovación cósmica no consistirá en una modificación natural sino en un soberano acto de libertad divina. Esta doble perspectiva guarda una justa valoración por lo creado, a la par que preserva la absoluta e irreductible soberanía divina en la Parusía. Plantear una resurrección de todo lo creado implicaría, por el contrario, concluir que, necesariamente, Dios debería dejar primero morir al universo con sus dinamismos inmanentes.

En consonancia con estos argumentos, sostiene este autor, el estado actual del cosmos sería una fase germinal para una nueva condición escatológica (tal como se señala en Rm 8,19s y en Concilio Vaticano II, 2000a, n.48), que sólo Dios podrá dar nacimiento con un puro don sobrenatural; en caso contrario, (tal como la ciencia nos señala) culminaría en la universal esterilidad física. Para la consumación final será menester una intervención particularísima de Dios, y por lo tanto no podrá reducirse a un mero proceso natural de las causas segundas. El Dios Trino, interna comunión de sobreabundante vitalidad, impedirá que su creación caiga en una extinción de sus leyes físicas y en la aniquilación irreversible de sus fuentes cósmicas de energía, con la subsiguiente imposibilidad de supervivencia de cualquier forma de vida. Antes bien, el cosmos será transfigurado para convertirse en el perfecto hogar de los resucitados a imagen de Cristo Glorificado.

Vista desde esta perspectiva, la $2^{\text {a }}$ Ley de la Termodinámica pierde su connotación de temida fuerza disgregadora, y se transfigura en signo de la contingencia del universo creado. Así como existe una relativa autonomía y el profundo potencial del cosmos, la entropía alude a la imposibilidad de pensar un cosmos autosuficiente. En la Parusía, el tiempo será asumido y rescatado por el Señor en la totalidad de su duración creada; entonces ya no medirá la degradación entrópica, sino la plenitud inagotable de la presencia divina en su creación (según lo anunciado en 1 Co 15,28 y en Ap 21,3). De forma consonante a la redención del hombre, y con similar acto de absoluta gratuidad, Dios rescatará al cosmos, de lo que habría sido su destino natural si no hubiese existido el acontecimiento de la Pascua.

Como acotación final, abierta a una ulterior investigación y debate, propone Bollini (2007) asumir en este punto la expresión de Santo Tomás y referirse a una innovación (innovatio) del universo en lugar de su renovación (re-novatio). El primer término denota mejor la idea de la introducción de algo nuevo en la interioridad del ente proveniente del exterior. Desde esta interpretación etimológica, se puede expresar más cabalmente la convicción de que Dios Trino introducirá una novedad en la trama misma de la creación, en lugar de reemplazarla por otra realidad. La idea del término innovar recoge la necesaria dialéctica continuidad discontinuidad entre el cosmos presente y el adviniente: el prefijo "in" 
rescata la identidad de este mismo mundo, mientras que la raíz "novar" salva la dimensión de ruptura.

Agrega Bollini (2007), siguiendo la enseñanza de Moltmann, que esta innovación debe incluir una purificación de las estructuras de pecado en el mundo, de modo que tal vez sea más exacta y completa la idea de una innovación purificadora y consumadora del universo.

En cuanto a la futura situación histórica del hombre, inmediatamente previa a esta consumación cósmica, tampoco caben afirmaciones taxativas sino esperanzas fundadas en la misma fidelidad divina. Algunos textos del Magisterio nos previenen de concebir la Parusía sólo como meta-histórica. Tal como asevera la Comisión Teológica Internacional, la Parusía es "un acontecimiento concreto conclusivo de la historia" (Comisión teológica internacional, 1990: n.2.1; Congregación para la doctrina de la fe, 1979: n.5; Concilio Vaticano II, 2000b, n.39); por su parte, Juan Pablo II (1994) expresa que con la venida de Jesucristo "se inicia el tiempo de la Iglesia que durará hasta la Parusía" (n.10). La fe cristiana espera un éschaton que, siendo en sí mismo trans-histórico, advendrá a y en la historia humana. Por ende, parece razonable sostener que persistirá alguna configuración de esta humanidad, entendida como: una comunidad de seres corpóreoespirituales creados, situados en la trama de la presente historia inaugurada en el planeta Tierra, y llamados y redimidos por Dios Trino.

Por eso, a la esperanza ya formulada respecto del cosmos, se suma aquí la confianza de que el éschaton advendrá antes de que el hombre desaparezca del universo. Podemos proponer, pues, la esperanza de que el hombre en comunidad se encuentre aún peregrinando en la historia de la salvación divina cuando advenga la consumación cósmica; caso contrario se estaría postulando una disociación platónica entre hombre y mundo, por la que para aquellos que ya salieron de la historia por su muerte dejaría de gravitar la realidad de este universo peregrino. Al depositar nuestra confianza en la vida sobreabundante del Dios Trino, surge, en efecto, la esperanza de que Él habrá de intervenir no sólo antes de que la creación pierda su capacidad de alumbrar vida, sino también, fiel a su promesa, antes de que su máximo fruto, el hombre mismo, desaparezca como especie. Dado que sabemos que el poder destructor del hombre o del cosmos nunca podrá preponderar sobre el poder creador de Dios, confiamos en este rescate universal. Asimismo, tampoco parece consonante con el Evangelio el panorama de un cosmos ya sin vida inteligente y espiritual, en el que el Dios donante haya clausurado ya su comunicación sobrenatural a sus creaturas. 


\section{REFLEXIONES FINALES}

¿Qué decir de estas dos posiciones tan diferentes? Nos parece que, en un tema tan difícil, Polkinghorne satisface las exigencias de una escatología que asume en serio el problema de la entropía y el de la nueva cosmología.

En efecto, la teología no está acostumbrada a reflexionar contando con las grandes dimensiones de nuestro universo ${ }^{11}$. De manera más o menos inconsciente es antropocéntrica: nos presenta una historia de la salvación terrestre que llegará a la plenitud en el acontecimiento de la parusía en un periodo más o menos cercano. Ya la perspectiva de una especie humana que puede durar unos cuantos millones de años está ausente. Pero, más radicalmente, no se ha puesto a pensar en la posibilidad de que haya otras creaturas personales en este vasto universo de miles de millones de galaxias. ¿La salvación es terrestre o universal? Es impensable una salvación de nuestro planeta con independencia del resto del universo. Ella sólo puede ser universal y demorar muchísimo tiempo.

Por otra parte, la humanidad resucitada sólo puede habitar en un mundo profundamente nuevo. Polkinghorne habla de otras leyes naturales y otro tipo de presencia divina, y tiene razón. A veces, en algunos autores, parece que hay sólo una suave transición entre esta historia y la definitiva ${ }^{12}$.

Polkinghorne rechaza la posibilidad de una intervención fuerte, extraordinaria, de Dios que transforme y lleve a plenitud a este universo. Prefiere hablar de una "transformación" que es en realidad la creación de otro universo, que recoge lo mejor de éste. Le parece que es más justo recalcar el respeto de Dios por los procesos naturales e históricos de este mundo que ha creado.

Hay dos puntos que son problemáticos en Polkinghorne. En primer lugar, la disolución de la Parusía tal como la entiende el Nuevo Testamento: como intervención de Dios que lleva a plenitud la historia y el cosmos. Pareciera que ella se identifica con la nueva creación y que por tanto no es un acontecimiento de este mundo.

El segundo punto es el de la extinción de este universo. No sólo es problemático el dolor que acarrearía la extinsión de especies vivas (y conscientes como en el caso del ser humano) sino también la desaparición del sujeto de la salvación (salvo las almas humanas que estarían con Dios).

Bollini nos presenta una visión mucho más cercana a las fuentes bíblicas y tradición de la Iglesia. La Parusía ahora es una intervención directa y fuerte de Dios que lleva a plenitud la historia de la humanidad y

\footnotetext{
11 Solo a modo de ejemplo: Moltmann, 2004: 201-208; Ruíz de la Peña, 1996: 132-140; Pozo, 1968: 124-135.

12 Como en el texto de Moltmann de la nota anterior.
} 
del cosmos. Se trata de un rescate, sí, pero que responde también a los anhelos e impulsos inscritos en su creación.

El punto más problemático, a nuestro juicio, es que, de existir en el universo otras especies conscientes como la humana, la Parusía también debiera constituir la plenitud de la historia de esas especies. Las hipotéticas historias de la salvación que ellas pudieran tener coincidirían en culminar al mismo tiempo con la humana; algo no imposible pero poco probable.

En síntesis, y respecto de nuestro tema de la entropía, Polkinghorne afirma que ella tendrá lugar, pero que no constituye la última palabra de la realidad, dado que posteriormente Dios dará lugar a una nueva creación.

Bollini piensa, en cambio, que la temida entropía no tendrá lugar, ya que Dios intervendrá rescatando a su creación antes de que ella se produzca, con lo que cambia de significado: simplemente ella será signo del carácter finito de nuestro mundo, necesitado de la plenitud de Dios.

\section{REFERENCIAS}

Barbaglio, G. (1990). Le lettere di Paolo 2. Roma: Borla.

Bardeen, J., Carter, B. \& Hawking, S. (1973). The Four laws of black holemechanics. Communications. Mathematical Physics, (31), 161-170.

Bekenstein, J. (1973). Black holes and entropy. Physical Review D, 8(7), 2333-2346. Bollini, C. (2007). Fe cristiana y final del universo: la escatología cósmica a la luz de los modelos actuales de la cosmología científica. Buenos Aires: Tesis de doctorado, Universidad Católica Argentina, Facultad de Teología. Disponible en bibliotecadigital.uca.edu.ar/repositorio/tesis/fe-cristiana-final-universoescatologia.pdf

Bollini, C. (2010). El desafío de la entropía a la teología. Revista Teología, 47 (101), 69-90.

Cervantes, J. (1995). Segunda Carta de San Pedro. En S. Guijarro y M. Salvador (eds.), Comentario al Nuevo Testamento (pp. 663-664). Estella: Verbo Divino.

Congregación para la doctrina de la fe (1979). Carta sobre algunas cuestiones referentes a la escatología. Disponible en http://www.vatican.va/roman_curia/congregations/cfaith/documents/rc _con_cfaith_doc_19790517_escatologia_sp.html

Comisión teológica internacional (1990). Algunas cuestiones referentes a la escatología. Disponible http://www.vatican.va/roman_curia/congregations/cfaith/cti_documents /rc_cti_1990_problemi-attuali-escatologia_sp.html

Concilio Vaticano II (2000a). Constitución dogmática Lumen gentium. (Segunda edición). (L. Amigo y R. Herrera, Trads.) Madrid: BAC.

Concilio Vaticano II (2000b). Constitución pastoral Gaudium et spes. (Segunda edición). (L. Amigo y R. Herrera, Trads.) Madrid: BAC.

Einstein, A. (1916). Die Grundlage der allgemeinen Relativitätstheorie. Annalen der Physik, 7(49), 769-822. 
Galloway, A. (1952). The cosmic Christ. A development and explanation of the doctrine of cosmic redemption in Biblical Theology. New York: Harper \& Brothers.

Hawking, S. (1975) Particle Creation by Black Holes.Communications. Mathematical Physics, 3(43), 199-220.

Jeans, J. (1942). The Mysterious Universe. New York: Macmillan.

Juan Pablo II. (1994). Carta Apostólica Tertio Millennio Adveniente. Santiago: San Pablo.

Kaku, M. (1995). Hyperspace: A scientific odyssey through parallel universes, time warps, and the tenth dimension. Oxford: Oxford University Press.

Kondepudi, D. \& Prigogine, I. (1998). Modern thermodynamics: From heat engines to dissipative structures. Chichester: John Wiley \& Sons Ltd.

Moltmann, J. (1987). Dios en la creación. Salamanca: Sígueme.

Moltmann, J. (2004). La venida de Dios. Salamanca: Sígueme.

Mora, C. (2007). Carta a los Colosenses. En A. Levoratti (Ed.), Comentario bíblico latinoamericano (pp. 957-978.). Verbo Divino, Estella.

Papanicolau, J. (2005). Cristología cósmica. Buenos Aires: Epifanía.

Pérez, G. (1995). Carta a los Colosenses. En S. Guijarro \& M. Salvador (Eds.) Comentario al Nuevo Testamento (pp. 555-556). Estella: Verbo Divino.

Polkinghorne, J. (2002). The God of hope and the end of the world. Connecticut: Yale University Press.

Polkinghorne, J. (2007). La fe de un físico. Estella: Verbo Divino.

Pozo, C. (1968). Teología del más allá. Madrid: BAC.

Ruíz de la Peña, J. L. (1996). La Pascua de la Creación. Madrid: BAC.

Teilhard de Chardin, P. (1967). El medio divino. Madrid: Taurus.

Wilkens, U. (1992). La Carta a los Romanos II. Sígueme, Salamanca.

Sumario: Introducción; 1. Termodinámica, entropía y el destino del universo; 2. El fin del mundo en la revelación bíblica y magisterio eclesial; 3. Reflexión actual; Referencias. 